\title{
Escalation in International Conflict Management: A Foreign Policy Perspective
}

Molly M. Melin

Loyola University Chicago, mmelin@luc.edu

Follow this and additional works at: https://ecommons.luc.edu/politicalscience_facpubs

Part of the International Relations Commons

\section{Author Manuscript}

This is a pre-publication author manuscript of the final, published article.

\section{Recommended Citation}

Melin, Molly M.. Escalation in International Conflict Management: A Foreign Policy Perspective. Conflict Management and Peace Science, 32, 1: 1-22, 2015. Retrieved from Loyola eCommons, Political Science: Faculty Publications and Other Works, http://dx.doi.org/10.1177/0738894214545033

This Article is brought to you for free and open access by the Faculty Publications and Other Works by Department at Loyola eCommons. It has been accepted for inclusion in Political Science: Faculty Publications and Other Works by an authorized administrator of Loyola eCommons. For more information, please contact ecommons@luc.edu. (c) $(7)(-)$

This work is licensed under a Creative Commons Attribution-Noncommercial-No Derivative Works 3.0 License. (c) Molly M. Melin, 2014 


\title{
Escalation in \\ International Conflict Management: \\ A Foreign Policy Perspective ${ }^{1}$
}

\author{
Molly M. Melin \\ Loyola University Chicago \\ Department of Political Science \\ mmelin@luc.edu
}

\section{Published in \\ Conflict Management and Peace Science}

\footnotetext{
${ }^{1}$ This paper was prepared for presentation at the annual meeting of the International Studies Association, San Francisco, CA, April $3^{\text {rd }}-6^{\text {th }}, 2013$ and the annual meeting of the International Society of Political Psycology, July 8-11, 2013, Herzliya, Israel. The project was funded with a generous grant from the Folke Bernadotte Academie. The author would like to thank Paul Poast, Renatto Corbetta, Karl de Rouen, Govinda Clayton, Ranan Kuperman and Christopher Darnton for their helpful comments. Sara McKeever, Nelson Wainwright and Jessica Mecellem provided invaluable research assistance.
} 


\begin{abstract}
Efforts to resolve interstate disputes are often characterized by repeated engagement and evolving strategies. What explains a state's decision to continue conflict resolution efforts but escalate their management strategy? Drawing from foreign policy literature, I argue third parties escalate policies both in response to past failures, shifting conflict dynamics, and their relationship with the disputants. Analysis of management efforts from 1946 to 2001 reveals that the changing nature of the conflict, policy failures and relationships between the third party and disputants are integral to understanding the management decision process, but the effects of these factors depend on the management history.
\end{abstract}

Keywords: Conflict management, Militarized Interstate Disputes, Mediation, Intervention 
Management begets management. This is one of the most universal findings in the conflict management literature: a history of managing a conflict encourages the same state to manage the conflict once again (Greig 2005; Regan and Stam 2000). While third parties with previous involvement as a conflict manager are likely to remain involved, it is unclear the extent to which their policies and approaches change. What explains a state's decision to remain involved in efforts to resolve a conflict but change their strategy of managing the conflict? How can we explain management choices and policy escalation? Are third parties responding to past failures, changes in the nature of the dispute, or is this decision reflective of a more self-interested process?

Policy escalation reflects strategic third party management decisions. This paper argues that states escalate management strategies as a response to several underlying conditions. Most obviously, states may adopt a new management technique in an effort to more successfully resolve the conflict. Past strategies may have been ineffective, or conflict dynamics may have shifted such that a new approach is more appropriate. Conversely, management changes may be reflective of strategic relationships between the third party and the disputants, and intervention behavior can reflect state ties rather than conflict dynamics. This paper further explores the role these factors play in the conflict management process.

A study of intervention policy dynamics adds several important new dimensions to understanding international conflict resolution. First, this represents a first effort to open the "black box" of conflict management, analyzing what happens between the start and end of third party involvement. Second, I adopt an integrative definition of intervention, including various mechanisms of third party conflict management and thereby offering 
insights about their interplay and sequencing. Finally, as a willingness to try multiple intervention techniques reveals information about the third party commitment to resolving the conflict, understanding policy changes offers a mechanism of capturing third party resolve and commitment to conflict resolution.

The paper begins with an overview of the literature on which it will build: that on foreign policy change, conflict management and mediation. I then offer a theory of when third parties are likely to adopt escalatory policies of conflict management and when they are likely to remain involved using the same techniques, which draws from the foreign policy literature. I argue third parties change policies both in response to past failures and shifting conflict dynamics. Changes in policies may also be reflective of the strategic relationship between the third party and disputants. Censored probit analysis of 269 management efforts from 1946 to 2001 reveals that the changing nature of the conflict, policy failures and relationships between the third party and disputants are integral to understanding the management decision process, but the effects of these factors are dependent on the management history. In circumstances following verbal and diplomatic attempts, biased states, or those with strong ties to only one of the disputants, are significantly more likely to escalate policies regardless of previous outcomes. Following strategic non-intervention, however, third party ties to both actors encourage policy escalation. These results contribute to and extend the vast literature on bias and conflict management. I conclude by highlighting directions for future research.

\section{THE LITERATURE OF POLICY CHANGE AND MANAGEMENT DECISIONS}

To explain escalations in conflict management policy, this paper seeks to link the literatures on foreign policy change, which mostly focuses on the process of US foreign 
policy decision-making (Clark 2001, 2, Clark, Nordstrom, and Reed 2008, Clark and Reed 2005), and on conflict management, which treats various management techniques as distinct events. While policy inertia is present and perhaps even dominant, policy changes do occur and are worth exploring (Gustavsson 1998). Policy substitution has been shown to occur in the management of both civil (Regan 2000) and international (Oswiak 2014) conflict, but it is unclear why states change and escalate policies when managing an interstate war.

Despite a focus on wholesale, comprehensive changes and restructuring (see, for example Hermann 1990), the literature on foreign policy change offers important theoretical insights into the state policymaking process. I broadly categorize the factors highlighted within the foreign policy literature as (1) contextual and (2) intervening factors. Contextual factors involve situational conditions, such as Goldmann's (1988) "stabilizers," which inhibit change even in the presence of pressure for change. ${ }^{2}$ Intervening factors are the dynamic events that push for change, such as Hermann's (1990) external shocks and domestic restructuring. ${ }^{3}$ A combination of contextual factors and intervening factors lead to the outcome of policy change (Holsti 1982, Hermann 1990). I consider these broad theoretical factors as they apply to changes in conflict management method.

Enormous strides have been made within the conflict management literature in recent years. Since focusing on management outcomes produces a selection bias (Greig

\footnotetext{
${ }^{2}$ These variables, which include thirteen international, cognitive, political and administrative stabilizers, affect whether or not sources of change actually set change in motion.

${ }^{3}$ Research within the foreign policy decision making literature examines a variety of influential factors, including the psychology of leaders, public opinion, bureaucracies, media, special interest groups, government structures, political structure and norms all as sources of policy change. As accounting for each of the possibly influential mechanism is beyond the scope of this paper, I draw from the theoretical contributions this literature makes.
} 
2005, Gartner and Bercovitch 2006, Svensson 2006), scholars have begun to understand management occurrence and generate a more complete picture of the management process. For example, we know mediation is more likely to occur in international rivalries than less intense conflicts (Bercovitch and Diehl 1997) and in international disputes characterized by high complexity, high intensity, long duration, and unequal parties (Bercovitch and Jackson 2001). We also know that the characteristics of the dispute and the disputants explain mediation occurrence (Greig 2005), and the mediators account for their relationship to the disputants (Melin 2011) and ability to transform the conflict before acting (i.e. Bercovitch 2002, Touval and Zartman 2001).

This paper represents is an attempt to understand the substitutive and iterative nature of conflict management. While scholars are beginning to understand third party involvement and outcomes, we have little information about what goes on between the start and end of such efforts. The first contribution of this project is therefore to examine the dynamic nature of third party involvement. Third parties' strategic selection of management policies has important implications for both the characteristics of management and its outcomes. Failing to account for what we know about actors' strategic choice of involvement and method (Melin 2011) and the characteristics of disputes that require outside assistance for resolution (Gartner and Bercovitch 2006) would introduce selection bias. Addressing variation in third party management techniques enables me to account for each of these strategic processes and avoid reaching incorrect conclusions due to selection bias (see Fearon 2002).

I also seek to address another common problem in existing literature. Most conflict management scholarship isolates the outcome of interest as a discrete variable 
where a reference category encompasses all behavior other than the outcome of interest (Clark, Nordstrom, and Reed 2008). Other policy alternatives are unspecified and aggregated as something other than the outcome of interest. "Mediation" is contrasted with "no mediation," "sanctions" with "no sanctions," and "peacekeeping" with "no peacekeeping." Many existing studies examine policies of military intervention (see Regan 1996), diplomatic approaches (see Mack and Snyder 1957, Kleiboer 1996, Pruitt 1981), mediation (Bercovitch, Anagnoson, and Wille 1991, Regan and Stam 2000), and economic sanctions (Hufbauer and Schott 1983, Li 1993, Weiss 1999) independently of one another. ${ }^{4}$ My second contribution is to integrate these literatures by examining strategy iterations. These disparate literatures can and should be united with research on other methods of conflict management (see Dixon 1996, Regan 2000, Frazier and Dixon 2006b, Melin 2011, Beardsley and Lo 2013 for works that consider the interplay of substitutable management techniques).

Finally, this paper offers a mechanism of quantifying intervener commitment. A willingness to try multiple intervention techniques reveals information about the third party commitment to resolving the conflict, as third parties with a strong desire to peacefully resolve a conflict are more willing to employ multiple intervention techniques. Third parties that adopt multiple strategies in the same conflict signal interest in the conflict and its resolution. Third parties that focus their energy on conflict resolution and repeatedly engage the disputants simultaneously build rapport and trust, increasing the

\footnotetext{
${ }^{4}$ While examining these different methods of management jointly is an important step to understanding the conflict resolution process, the currently accepted categorizations are admittedly not arbitrary. It is logical to examine these actions separately if seeking to understand the occurrence of multilateral efforts. When examining such efforts from the supply side, however, creating delimited categories poses serious threats to the accumulation of knowledge (Starr 2000).
} 
likelihood of effectively resolving the conflict. Engaging committed conflict managers will increase the likelihood that they generate a lasting peace agreement.

\section{MANAGEMENT STRATEGIES, POLICY CHANGE AND ESCALATION}

Conflict management represents an attempt to do something about reducing,

limiting or eliminating the level, scope and intensity of violence in conflict and building a structure where the need to resort to violence in future conflicts is controlled. ${ }^{5}$ This paper focuses on nonbinding unilateral and multilateral management, examining the conflict management process from the third party's viewpoint. ${ }^{6}$ I examine changes in management tactics among verbal management, administrative support, diplomatic efforts, economic sanctions, and peacekeeping rather than singularly focusing on one management mechanism (see Table 1 for descriptions of these strategies).

Scholars adopt varied approaches to defining escalation and change in foreign policy. ${ }^{7}$ In this paper, I adopt Goldmann's (1988) simple definition as "either a new act in a given situation or a given act in a situation previously associated with a different act." This definition is appropriate for examining shifts in management policies since these changes are not necessarily reflective of large-scale overhauls of a state's broader policy agenda. Hermann (1990) discusses these as "adjustment" and "program" changes, which

\footnotetext{
${ }^{5}$ This paper does not seek to explain outside parties that join as an additional disputant (see (Singer, Bremer, and Stuckey 1972); (Corbetta 2010)) but instead focuses on third parties that act as conflict managers.

${ }^{6}$ Broadly speaking, the numerous tools available for conflict prevention, management, and resolution can be grouped into three different categories: (i) unilateral, which involve conflict management without the consent of the disputants, such as military intervention (ii) bilateral, which involves direct talk between the disputants, such as negotiation, and (iii) multilateral, which takes place with the consent and cooperation of the disputants, such as mediation or adjudication. By focusing on unilateral and multilateral efforts, I offer a supply side approach to management. Whether the effort is unilateral or multilateral has important implications for the probability that the effort will be successful.

${ }^{7}$ While some scholars focus on a wide reaching shift in a state's external relations (Deutsch 1973, Maoz 2004), others have developed extensive typologies that encompass graduated levels of change (Holsti 1982).
} 
entail tactical movements in the realization stage of a policy or the methods and means used to meet a foreign policy objective.

I focus on policy escalation as employing more costly management techniques, which may involve cessation of initial management method or the use of other tools in addition to the initial method. Shifts in management policy can be categorized on the basis of variation in the actors and actions. In the first, what I refer to as conflict-based change, similar responses are employed in different conflicts. Thus, the change is in the identity of the disputants. Consider the varied uses of mediation as a form of conflict management: US mediation of the conflict between Israel and Egypt in the 1970s, the Vatican's mediation in the Falkland conflict between Argentina and the UK in 1982, and Congo's mediation of the conflict between Burundi and Rwanda in 1966. Thus, in conflict-based change, the policy employed is the same but the conflict (and possibly, but not necessarily, the third party) is different.

In policy-based change, similar conflicts are managed differently. Consider the UN observers originally sent into Yugoslavia in 1992 compared to the later NATO military intervention in Kosovo. As was the case in the international reactions to Yugoslavia and Kosovo, change is likely the result of learning. In policy-based change, the policy employed (and perhaps, although not necessarily, the third party) differs despite similarities across conflicts.

Finally, different management techniques are combined with one another in management-based change. George H.W. Bush's verbal response to Iraq's invasion of Kuwait, "This will not stand," was followed with military intervention. Economic sanction, diplomatic efforts, and peacekeeping efforts are substitutable ways of managing 
a conflict. Thus, in management-based change, the conflict and third party remain the same, but the approach to management differs.

Since each type of change likely has different causes and often involves different actors, creating an understanding of when and why each occurs is beyond the scope of a single theory or paper. This paper therefore focuses on the last policy change type, management-based change, which involves the same third party adopting a new management policy in a conflict. More specifically, I examine the direction of these changes, or those that constitute policy escalation. Policy escalation involves adopting a new, more invasive (and likely costly) conflict management policy, as Table 1 summarizes. Adopting a strategy to the right of the initial strategy constitutes a policy escalation, as the strategies are ordered by the costs the third parties incur (Owsiak 2014).

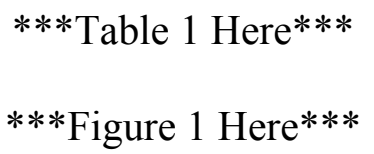

Figure 1 shows the frequency of each initial and follow-up strategy. Less costly efforts are common initial strategies when the third party chooses to act at all, as verbal (53\%) and diplomatic (40\%) approaches are employed at a higher rate than economic $(6 \%)$ and peacekeeping operations (1\%). By far the most common policy, however, is one of nonintervention, which is the initial strategy in $99 \%$ of all third party-conflictyears. Figure 1 also shows the frequency of different secondary policy choices. Deescalatory strategies are the most common ( $42 \%$ of cases) choice after an initial effort concludes. Most third parties de-escalate to the point of exiting for management altogether, and verbal efforts are the only form of de-escalation that occurs, used in four cases. Choosing the same strategy occurs infrequently (18\% of cases), and only following 
diplomatic and verbal strategies. There is much more variation, however, in escalatory policy choices. Third parties follow initial techniques with verbal (56\%), diplomatic (38\%), economic (4\%) and peacekeeping (2\%) strategies. Thus, while the theoretical approach certainly has important implications for de-escalatory behavior in conflict management, much of the interesting variation in second effort policy choices occur in the decision to escalate. I therefore focus on escalation for reasons of both interest and empirical necessity. The next section explores when and why third parties change from their initial strategy to a more invasive one.

\section{A THEORY OF MANAGEMENT DECISIONS}

What explains escalations in conflict management policy? When and why do third parties change their response to a conflict to adopt a more invasive policy? While the answer to this question initially seems simply that the initial policy is not producing the desired result, further exploration of the management process reveals variation in policy escalations that incorporates more than policy failures. Third parties may meet their goals then adopt new policies. In addition, states must account for their own commitment to resolving the conflict and the level of involvement that is in their interests. I broadly categorize causes of escalation as (1) contextual factors, which provide background information and tell us about dispute salience to the third party, and (2) intervening events, which create pressure for change through shifts in environmental conditions or negative feedback.

\section{Contextual Factors and Escalation}

Contextual factors reveal information about the setting in which policymakers act, providing important background to policy decisions. Policy makers may be more immune 
to pushes for escalation in some circumstances, as in the presence of Goldman's (1988) stabilizers. According to Goldman, "stabilizers" that can inhibit change even in the presence of pressure for change. These variables, which include international, cognitive, political and administrative stabilizers, affect whether or not sources of change actually set change in motion.

In conflict management settings, the strategic relationship between the third party and disputants provides important context to the foreign policy decision process. That state relationships (whether cooperative or conflicting) are often very stable across time, especially in the post-Cold War era (Wohlforth 1999), means they create a consistent setting in which policy makers decide upon management decisions. State relationships are an important contextual factor in policymaking since they provide information about how much the third party values conflict resolution (Melin 2011). State relationships include ties through alliances, trade and geography. Those states that share an alliance, trade with, or are geographically proximate to the disputants have strong ties to the actors involved. Strong third party ties to disputants encourage interveners to use employ any tools at their disposal to resolve the conflict, thereby encouraging policy escalation when necessary. Consider Germany's involvement in the break up of Yugoslavia, wherein they continued efforts despite repeated failures. ${ }^{8}$ Since third parties with strong ties to the disputants are more likely to desire peaceful conflict resolution, these states are willing to employ multiple intervention strategies and escalate when necessary. Conversely, if policy makers do not place high value on settling the dispute in question, then it will not

\footnotetext{
${ }^{8}$ Germany has strong strategic, economic, religious ties to both Slovenia and Croatia, which encouraged its active engagement during the breakup of Yugoslavia. It was the first country to recognize Slovenia and Croatia in the European Community and remained engaged in the diplomatic and eventual military interventions. Germany's involvement reflects a long time engagement in the country (Libal 1997), and some consider Germany to have been "Yugoslavia's best diplomatic friend" (Nielsen 1999).
} 
gain allocations of the actor's limited resources (Goldmann 1988). As conflict management is not costless, third parties must have sufficient interests at stake in the conflict to voluntarily become involved in an already difficult situation (Powell 1993, Palmer 1990, Clark 2001). The strategic interests of the mediator are highlighted in the mediation literature in terms of bias (Melin 2011, Terris and Maoz 2005), credibility (Favretto 2009, Kydd 2007, Rauchhaus 2006), and interests (Terris and Maoz 2005), as well as affecting engagement (Beardsley 2010, Melin and Svensson 2009).

Observable third party ties to disputants include the presence of alliances, trade interests and geographic proximity. Since conflicts involving allies threaten alliance partners, third parties have an interest in seeing these conflicts peacefully resolved (Melin 2011). Economic ties have been shown to increase communication between states, creating shared identity and values and to increase international intervention in civil wars (Greig and Regan 2008). Geographically proximate states, which regularly interact with the disputants and will be disproportionately affected by a neighboring conflict, are more likely to engage in conflict management (Kathman 2010, 2011). Common interests and threats mean third parties are going to have a greater interest in seeing the conflicts that affect their allies resolved, making them more likely to escalate policies when necessary. We can therefore expect that:

Hypothesis 1: Third parties with strong ties to the disputants are more likely to adopt escalating management policies.

\section{Intervening Factors and Change}

Intervening factors are dynamic events that push for change, such as shocks and restructuring (Hermann 1990). In one of the classic works on foreign policy change, 
Rosenau (1980) highlights the process of political adaptation to changes in the environment, writing that continuities and changes in policy are in response to internal developments and shifts in external circumstances. Policy makers adapt to changes in order to minimize costs and maximize opportunity for success. Later work by Goldmann $(1988,3-4)$, elaborates that while states "have a tendency to stick to their previous policies," there is also pressure "to adapt to changing conditions in their environment."

Within the conflict management environment, one important environmental change is policy feedback. The outcomes of past policies may create pressure for change or be stabilizing. While progress in past efforts encourages continued engagement, those that produce negative results create an atmosphere discouraging repeated attempts and increase third party exiting. Efforts that fail to produce any agreements or changes in disputant behavior do little to reward third party efforts and offer few incentives for future efforts.

Within the mediation literature, previous management experiences has been shown to play an important role in third party involvement, regardless of the previous effort's outcome (Rubin 1992, Bercovitch and Gartner 2006, Clayton and Gleditsch 2013, Greig 2005). Management efforts are not isolated events, as each incidence creates a history of the third party and disputant management experience. On the disputant side, prior efforts establish rapport and signal a commitment to conflict management. Previous disputant experiences with mediation signals a disputant's willingness to work with an outsider. In this broader process, previous involvement encourages future, more engaged efforts. 
Successfully accomplishing management goals is also likely to generate shifts in the nature of third party involvement. The third party can then set new goals and will revise its strategy in accordance with these goals. The likelihood that a third party escalates its policy in a conflict increases when some progress is being made yet not all issues are settled. These circumstances encourage the third party to remain involved since they now have a stake in the outcome and have seen some of their efforts come to fruition (Rosenau 1980). I therefore hypothesize that:

Hypothesis 2: When previous management policies attain their goal, third parties are more likely to adopt escalating management policies.

A second important environmental change involves shifting conflict dynamics. Increasing conflict severity, for example, provides additional sources of negative feedback and pressure for policy changes. The nature of the conflict in terms of intensity and potential for escalation plays an important role in mediation occurrence and outcomes (Richmond 1998). We know that as conflict severity increases, the additional costs encourage disputants to find a diplomatic solution (Regan and Stam 2000, Zartman 2000, Greig 2001). We also know that disputants are responsive to conflict dynamics and battlefield events in agreeing to mediation (Greig 2013). In the words of economist John Maynard Keynes, "When my information changes, I alter my conclusions." Since changing conflict dynamics are likely to create pressure for escalation, I expect:

Hypothesis 3: When the conflict escalates, third parties are more likely to adopt escalating management policies.

Understanding the nature of policy shifts requires that we consider the nature of previous policies. The decision to escalate is partially dependent upon the technique that 
was previously employed, as some techniques are more costly or likely to require additional third party action than others. Variations in the costs of management techniques offer different signals of third party intentions, commitment, and likelihood of escalating. Whereas military, economic and diplomatic efforts may entail high third party costs, verbal efforts and strategic inaction are essentially costless and entail little or no commitment, as a state at most risks its rapport with other actors. We can also distinguish verbal, economic and military efforts, which are unilateral in the sense that they do not require disputant cooperation, from diplomatic efforts, which are multilateral and require disputant cooperation. Based on the low level of sunk costs and the presence of many escalating policy options, we can expect to find that escalation is much more likely to follow less costly management efforts. Third parties with strong ties to both the disputants are willing to employ more costly methods of management (such as mediation and other diplomatic efforts) early in a conflict, whereas other third parties will either employ a low cost technique (such as calling for a ceasefire) or wait to act until the costs of involvement are lower (Melin 2011). We should therefore observe third parties with strong ties to the disputants being more likely to escalate following a policy of nonintervention. We can therefore expect to find:

Hypothesis 4: When previous management policies include non-intervention or verbal efforts, third parties with strong ties to the disputants are more likely to adopt escalating management policies.

Whereas policy failures and shifts in conflict dynamics provide an intermediate step in the form of intervening policy factors, the relationship establishes the setting for policy makers. Context conditions the effect that intervening factors can have on policy 
change. Thus, background factors and intervening factors lead to the outcome of policy change (Holsti 1982, Hermann 1990). In the next section of the paper, I empirically test the hypotheses that state relationships, combined with policy failures, management history and conflict dynamics generate policy change.

\section{DATA, MEASUREMENT AND METHODS}

Quantitatively testing my hypotheses requires data that reflect my holistic approach- data containing information on the many ways that a third party can manage an international conflict. To test my theoretical argument, I examine conflicts coded in the Dyadic Militarized Interstate Disputes data (Maoz 2005), focusing on interventions in interstate conflicts rather than civil wars. It is likely that domestic sovereignty poses a barrier to entry causing a selection effect in civil wars: those who act despite domestic nature of conflict are more likely to be committed. In addition, civil wars likely face different barriers to settlement for example, they often involve ethnic conflicts, which are indivisible and harder to resolve (see Svensson 2007b). It is therefore logical to expect that civil disputes would have different trends in long-term management as policy changes. Grieg and Diehl (2012) show that civil conflicts have a greater propensity for repeat mediation than do interstate conflicts $(6.4 \%$ of civil conflicts compared to $3.5 \%$ of international conflicts are mediated by the same mediator six or more times).

The pool of potential conflict managers incorporates actors with varied affiliations, including those acting as independent individuals, under a state banner, and those with international and nongovernmental organizations. I focus my analysis on statesponsored mediation for both theoretical and empirical reasons. As states are both the dominant actors in world politics and the most frequent mediators, there are ample cases 
to examine. It is also likely that state interests differ from those of other third parties (see Melin, Gartner, and Bercovitch 2013 for a discussion on state-led mediation).

\section{Outcome Variable and Model Specification}

The processes that lead to escalation are not separate from the processes that encourage third parties to remain involved as a conflict manager beyond an initial management attempt. As Regan argues, the decision to act and which strategy to employ are inseparable (2000). The dependence in these actions creates challenges for econometric estimation, since third parties cannot escalate or change policies unless they opt to remain involved. As a conflict becomes more difficult to resolve and requires greater action from a third party, the likelihood of management occurring decreases. That third parties are likely to exit conflicts where they expect success is unlikely creates truncated data. Predicting escalation and de-escalation using logit estimation would result in biased estimates, as sample selection would result from merging those cases in which no future management attempt occurred and those in which the same management method was employed. Failing to account for these related political processes in a unified empirical model will lead to biased estimates and incorrect conclusions (Reed 2000). Using a statistical model to identify the presence and structure of sample selection requires first identifying the selection process (which states remain involved as managers?) and then modeling the outcome of interest (which states adopt new management policies?) (Manski 1995). Poorly identified selection models will likely be biased and inefficient, hypothesis tests are likely to be incorrect, and estimates of the outcome equation will also be biased (Brandt and Schneider 2007). 
I estimate a censored probit model, which allows for the possibility of correlation in the equations' errors, to account for the selection problem. ${ }^{9}$ The Heckman model has an exclusion restriction that requires unique regressors that only appear in the selection equation (Achen 1986). Similar to simultaneous equation models, covariates must be both good predictors of the selection variable and uncorrelated to/ with the errors in the final outcome (Greene 2003). In this case, the decision to remain involved as a conflict manager (or select into the sample) is closely related to the decisions to employ the same approach or adopt a new management method. A key assumption in selection modeling is the inclusion of a robust selection equation, since this predicts whether observations will be censored. Running the selection equation by itself (as a probit) reveals $99 \%$ of the cases are predicted correctly using the specification presented below.

The first stage of the model predicts whether an initial Intervention occurs and a third party takes an action towards resolving the conflict, and the second stage examines when the third part escalates their management policy. Escalation takes place when a third party increases their intervention technique (see Table 1). This dichotomous measure assumes an increase in expenses and commitment from nonintervention to verbal, then diplomatic and administrative, followed by economic and military interventions (see Terris and Maoz 2005 for definitions and coding). ${ }^{10}$ Recurring intervention takes place in 190 efforts (third parties are involved in multiple management attempts in 62 percent of the 304 intervention cases). Third parties use the same

\footnotetext{
${ }^{9}$ It is theoretically possible that there are two different selection effects occurring: the selection of states that become involved and the selection of states that remain involved. However, I am not aware of a model that can model both processes simultaneously. And this is additionally complicated by the rarity of management events. I therefore focus on the first, and larger, selection effect: which states manage and the implications of this decision on escalation.

${ }^{10}$ Since non-intervention is a strategic foreign policy tool, it is included in the analyses presented below. Not taking any form of action can be a calculated response (Regan 2000).
} 
management methods in 57 of the cases, which is reflective of the inertia that structural constraints models highlight, as power relations and institutional conditions may prevent a change from taking place. Policy changes from non-intervention or a less burdensome intervention strategy (such as shift from verbal efforts to diplomatic approaches) takes place in 128 (or 42 percent) of the recurrent intervention cases.

\section{Explanatory Variables: Measuring Third Party Ties}

I create an index of the strength of the ties among states as a measure of the nature of the third party's relationship to each disputant. I employ the Alliance Treaty Obligations and Provisions data for information on if the third party has a defensive or offensive alliance with one or both states (Leeds et al. 2002), Barbieri's (1996) international trade data for above average values of merchandise that the disputants import from the third party and the third party imports from the disputants ${ }^{11}$, and the Correlates of War Contiguity data (Stinnett et al. 2002) for the presence of shared land or water borders. Studies have shown links between geopolitical interests (Crescenzi et al. 2012, Kathman 2011), trade (Crescenzi et al. 2005), alliances (Melin 2011) and third party management decisions. This is an annual ratio of the sum of the third party's ties (number of alliance, trade, and geographic ties) with a disputant to the sum of the third parties ties to all other disputants. This measure is used to capture the relative strength of this dyadic relationship to the third party's relationship with other states in ongoing disputes. Once the score for each dyad is calculated, I capture the relative strength of ties with One-sided Ties, which includes third parties who have one tie that is greater than one standard deviation from its tie to the other disputant, No Ties, which includes third

\footnotetext{
${ }^{11}$ I dichotomize this variable by coding the presence of above average trade ties as one, and average or below average trade ties and 0 .
} 
parties that have no ties to the disputants, and Two-sided Ties (the comparison category), which includes third parties with ties that lie within a standard deviation of each other.

\section{Explanatory Variables: Measuring Policy Feedback}

I expect that the failure of past policies to produce an agreement generates pressure to discontinue management efforts, whereas positive feedback should encourage third parties to remain involved and employ a variety of escalatory management techniques.

Positive Feedback: This is a dichotomous measure of the short-term outcome at the time the previous effort ended. Assessment is made as to whether or not the primary goal of the intermediary intervention was achieved at the end of fourteen days, coded according to the Third Party Intervention data (see Frazier and Dixon 2006a). ${ }^{12}$

\section{Explanatory Variables: Measuring Conflict Dynamics}

I hypothesize that changes in conflict dynamics should generate changes in management policy. More hostile conflict environments generate a different setting for interveners than to less hostile ones, and a post-conflict environment is substantially different from conflicts that have yet to escalate.

Conflict Phase: This variable measures shifts in policy dynamics by looking at changes in the phase of the conflict when the intervention occurs. Three dummy variables are used to capture changes in the conflict phase: crisis, coded one when at the start of a crisis but prior to the escalation to military hostilities and zero otherwise, hostilities, coded one at the start of military hostilities and zero otherwise, and post-crisis, coded one

\footnotetext{
${ }^{12}$ To further explore the role of previous outcomes, I also tested a measure of outcomes a year after the end of the intervention. For example, if a mediation effort was to assist in negotiating a ceasefire and the mediation effort created a ceasefire that has been upheld for at least 12 months, this is considered a successful result. I find that evaluating the long-term outcome of the management effort has no effect on either the onset of intervention or escalation.
} 
when the intervention began once the dispute is resolved and zero otherwise. The results are in comparison to pre-crisis circumstances (see Frazier and Dixon 2006a).

\section{Controls: Measuring Management Dynamics \& Third Party Characteristics}

Level of previous involvement: This variable accounts for the mechanism used in the previous conflict management attempt, as those states with a history of more invasive previous techniques have fewer policies to which they can escalate (Frazier and Dixon 2006a). Previous mechanisms include those summarized in Table 1. Previous verbal attempts are coded 1, diplomatic previous attempts are coded 2, economic are coded 3 and peace operations are coded 4.

Other third party successes: In the selection model, I also include a dichotomous measure, which may encourage additional management efforts (Frazier and Dixon 2006a). Both this and the previous involvement measures offer ways to capture the dispute's "importance" to would-be manager in understanding the decision to become involved, as strategic interests of the mediator have been shown to impact the decision to manage (Terris and Maoz 2005).

Capabilities: Mediators with material capabilities can incentivize agreements through offering carrots that increase an agreement's appeal or threatening sticks for failed compliance, thereby sustaining peace (Beardsley et al. 2006). States with abundant resources are also shown to be less constrained in their foreign policy choices as compared to those with few resources (Clark, Nordstrom, and Reed 2008, Siverson and Starr 1991). I therefore control for the third party's Composite Index of National Capabilities (Singer, Bremer, and Stuckey 1972). 
Regional Power: Another mechanism for capturing third party leverage is to account for regional powers. Third parties that are regional powers are likely to not only have the capabilities necessary to wage an intervention but also are likely to have the interest to do so. "Power mediators" have been shown to be more successful in generating military settlements in civil wars (Svensson 2007c). This measures whether or not the third party is considered a regional power, according to the Correlates of War data (Stinnett et al. 2002).

\section{RESULTS AND DISCUSSION}

Table 2 presents the results from censored probit models of escalation in management methods.

\section{***Table 2 Here***}

The first column predicts intervention occurrence, and the second column is the predictions of escalation. The third and fourth columns test for interactive effects between success and ties. The model of intervention occurrence echoes much of what has been found in the management literature: third party relationships with the disputants (Melin 2011), management history (Greig 2005; Regan and Stam 2000) and third party power (or leverage, see Beardsley 2013) are important predictors of management activity. The coefficient for rho reflects the correlation in the errors in the selection and outcome equations. While it is extremely sensitive to model specification, the negative sign tells us that any component making selection more likely makes the outcome less likely.

The first set of explanatory variables examines the role ties between the third party and disputant play, along with that of policy feedback. While I hypothesized that any ties will increase the likelihood of escalation, I find significant variation in those that 
have ties to only one disputant compared to those with ties to both disputants. We observe in the first model that third parties with one-sided ties are more likely to intervene but less likely to escalate policies compared to third parties with ties to both disputants. Having ties to one disputant decreases the probability of escalation by $40 \%$. In the model with interaction terms, the negative and significant relationship on the onesided ties coefficient tells us that those third parties with stronger ties to one state are $50 \%$ less likely to escalate policies when their previous policy was not successful. The positive and significant interaction term between one-sided ties and success tells us third parties with stronger ties to one state are more likely (with a $2 \%$ increase in probability) to escalate policies when their previous policy was successful. A third party with stronger ties to one disputant is almost fifty percent less likely to escalate when its previous efforts have not been successful and twenty percent more likely to escalate when previous efforts were successful. The coefficient on no ties and the interaction between no ties and success is not statistically significant, which tells us there may be little relationship between escalation and state relationships when the third party does not have ties to either disputant, regardless of previous policy success. Interestingly, as revealed by the lack of significance for the success coefficient, previous policy success does not have an independent effect on policy escalation when the third party has ties to both states. This builds on findings within the mediation (Clayton and Gleditsch 2013) and conflict management literatures that it is not the outcome of previous management attempts but the presence of previous efforts that inform future efforts.

These results suggest that policy feedback and ties among the actors are influencing the decision to escalate conflict management policies. States with stronger 
ties to one disputant (or biased states) are less likely to escalate when they have yet to accomplish the primary goal of their initial intervention. These same actors are more likely to select a more intrusive policy once those goals have been met. Together, these findings show that intermediaries with one-sided ties are responsive to policy feedback, waiting to first attain the goals of primary intervention efforts before escalating policies. Relationships and policy outcomes are less of a factor in circumstances that involve third parties without ties to either disputant or with ties to both disputants (or unbiased states).

Both models show that third parties are also responsive to shifting conflict dynamics. New policies are significantly more likely to be adopted when the conflict has recently become a crisis ( $2 \%$ increase in probability), has recent hostilities ( $3 \%$ increase in probability), or has been resolved (3\% increase in probability). This likely reflects the need for new approaches that adopt to changes in the conflict environment. The dynamics of the conflict play an important role in a third party's decision to adopt new management policies. $^{13}$

Management dynamics also play a strong role in the decision to escalate in both models. The measure for level of previous involvement has a strong, negative relationship with policy escalation. Were the previous management effort an intervention that involved the military, the state is $99 \%$ more likely to escalate policies as compared to if the previous effort only involved verbal threats. This suggests, as I expected, that the

\footnotetext{
${ }^{13}$ Since an overwhelming majority of the cases represent escalation from non-intervention, I reran the model defining escalation as a shift in active management strategies (excluding changes from nonintervention). The results of the ties and policy feedback remained the same. The coefficients for the measures of conflict dynamics, however, became negative while remaining significant. This suggests that changing conflict dynamics encourage more active involvement if the third party did not previously intervene but that shifting dynamics discourage changes in management strategy if the third party was already actively managing the conflict.
} 
more invasive and costly previous efforts at management were, the less likely a third party is to escalate policies.

\section{***Figure 2 Here***}

Figure 2 depicts the relationship between actor ties and escalation across various management histories. The graph highlights how the probability of escalation diminishes, reaching zero at efforts above diplomatic, as previous management efforts become more invasive. We also see that states with one-sided ties are generally less likely to escalate, but that the probability of escalation is much more divergent across state ties in management efforts following non-interventions and verbal efforts than in diplomatic efforts.

To better assess the role previous management techniques play in decisions to escalate, I run separate models comparing disputes that experience escalation following previous verbal appeals, diplomatic efforts, and those that have no management history. This helps to prevent inaccurate conclusions based on the skewed management histories. Table 3 offers a closer look at how escalation trajectories differ across various management histories.

\section{***Table 3 Here***}

Interesting variation in escalation trajectories exists across the different management histories. It is first important to note that previous policies of nonintervention make up an overwhelming majority of the cases, which highlights the necessity of examining results across management histories. Measures of policy feedback are omitted in the model of escalation after non-intervention, since there is no information about prior outcomes in these cases. With the exception of the now 
significant coefficient for the absence of ties, the results in the non-intervention model are strikingly similar to those in the pooled model discussed above. It appears that states that intervene after having a policy of non-intervention are significantly less likely to escalate if they have one-sided ties or completely lack ties to the disputants in comparison to those third parties with strong ties to both disputants. Third parties that wait to manage a conflict are more likely to escalate to intervention if they have strong ties to both disputants. It appears that, when escalating from non-intervention, it is the strength of the ties managers have to the disputants (rather than their biases) that encourage escalation.

State relationships play a different role in escalation decisions after verbal and diplomatic attempts, however. One-sided ties encourage policy escalation after both verbal and diplomatic attempts, regardless of the outcome of the previous effort. When the previous effort was a verbal attempt, the lack of third party ties to either disputant actually slightly decreases the probability of escalation. Bias, it seems, plays a stronger role in the escalation decisions after verbal and diplomatic attempts.

There is also interesting variation in the role conflict dynamics play in policy escalation across the different management histories. Shifting conflict dynamics, measured with new crisis, hostilities, or post-crisis circumstances all strongly encourage policy escalation after non-intervention. States are much more likely to adopt a more intrusive policy if the conflict dynamics shift following a policy of non-intervention. This story is quite different in efforts that follow verbal and diplomatic attempts, however. A new crisis following a verbal attempt actually decreases the probability of escalation, while hostilities have negative but insignificant effect as well. A shift to a post-crisis environment, however, encourages escalation after verbal attempts as well. Conflict 
dynamics appear to play little role in the escalation decisions following diplomatic efforts.

The coefficient for rho remains significant across each model, reflecting the high correlation in the errors in the selection and outcome equations. Although sensitive to model specification, the negative sign tells us that any component making intervention more likely makes escalation less likely after non-interventions, whereas the positive signs tells us that circumstances encouraging intervention also encourage escalation after verbal and diplomatic attempts.

\section{CONCLUSION}

Third parties often make salient contributions to resolving international conflicts through generating significant shifts in the conflict environment. While third parties can create changes within the conflict, they also respond to these changes. The management process is therefore often an adaptive one, as third parties learn and adapt their policies to an ever-changing conflict environment. In addition, however, third parties account for their ties to the disputants, as these ties set the stage for how all other information is processed.

What factors explain a third party's decision to escalate their strategy of conflict managing? This paper has argued that, while third parties respond to past failures and changes in the nature of the dispute, management decisions are also reflective of state relationships and previous techniques. States adopt changes according to policy feedback and shifting conflict dynamics. In addition, management changes reflect the strategic relationships between the third party and the disputants. I also show that a third party's decision to escalate management policies relates to the previous management tools 
employed, and that the effects of ties and conflict dynamics depend on this management history.

In further exploring the role these factors play in the conflict management process, this paper opens the "black box" of conflict management, analyzing what happens between the start and end of third party involvement. I adopt an integrative definition of intervention, including various mechanisms of third party conflict management, thereby pushing beyond the challenges of foreign policy substitutability problematic in much of the conflict management literature. Since a third party’s willingness to try multiple intervention techniques reveals information about its commitment to resolving the conflict, understanding policy changes offers a mechanism of capturing third party intent and resolve.

The findings here add an interesting new dimension to the vast literature on the role of state relationships and conflict management. The role of relationships in management activities has been a topic of great debate (Favretto 2009, Kydd 2007, Rauchhaus 2006). I further explore the role unsymmetrical ties and bias play in management through comparing the escalation of biased and unbiased management efforts. Ties can provide both the credibility (Terris and Maoz 2005) and bias (Favretto 2005) that have been shown to play important roles in the decision to become involved. My finding that biased third parties are more likely to escalate following verbal and diplomatic attempts sheds further light on the finding that these third parties will be capable of pressuring the disputants to find a peaceful end to conflict (Svensson 2007a, Savun 2005). Biased third parties may not be successful only because they have leverage, but also because they are willing to implement multiple management tools. 
Change and continuity are an integral part of the conflict management process. Much of the existing literature focuses on second attempts as trying the same method (as with the crude use of a "previous mediation" variable to capture interdependence between efforts, see Bercovitch and Gartner 2006 for a discussion) or as completely independent from the first (by adjusting standard errors to sustain this assumption, see Freedman 2006 for a discussion). However, multiple interventions often involve changes in intervention strategy. As strategic actors, third parties carefully choose their management policies and consider their possible outcomes. The data employed within this research shows that third parties are not adopting escalatory management techniques solely in response to past failures. This paper seeks to build on the works of those exploring the importance of interdependence between conflict management efforts (Heldt 2009, Owsiak 2014). While these papers offer a glimpse into the dynamics of conflict management, important questions remain involving exiting, cycling between managers, and the implications for creating a durable peace. Although these questions are beyond the scope of this paper, they are important questions that will further our understanding of strategic assessment in conflict management policy choices. 